\title{
REVIEW
}

\section{A biomechanical review of factors affecting rowing performance}

A Baudouin, D Hawkins

Br J Sports Med 2002;36:396-402

This review analyses rowing by linking the biological and mechanical systems that comprise the rowing system. Blade force was found to be the only propulsive force to counter the drag forces, consisting of both air drag and hydrodynamic drag, acting on the system. Vertical oscillations of the shell are shown to have minimal impact on system dynamics. The oar acts as the link between the force generated by the rower and the blade force and transmits this force to the rowing shell through the oarlock. Blade dynamics consist of both lift and drag mechanisms. The force on the oar handle is the result of a phased muscular activation of the rower. Oar handle force and movement are affected by the joint strength and torque-velocity characteristics of the rower. Maximising sustainable power requires a matching of the rigging setup and blade design to the rower's joint torque-velocity characteristics.

Coordination and synchrony between rowers in a multiple rower shell affects overall system velocity. Force-time profiles should be better understood to identify specific components of a rower's biomechanics that can be modified to achieve greater force generation.

See end of article for authors' affiliations

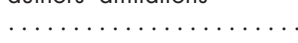

Correspondence to: Dr Hawkins,

One Shields Avenue, Room 275 Hickey Gym,

University of California,

Davis, Davis, CA 95616

USA; dahawkins@

ucdavis.edu

Accepted 8 July 2002
S uccess in the sport of rowing requires a powerful biological system (the rower) and an appropriately designed mechanical system (the shell) that effectively uses the rower's power and minimises drag forces acting on the shell and rower. Identifying rower attributes, shell design characteristics, and rowing motion dynamics that are most effective for maximising sustainable shell speed requires a thorough understanding of the interactions between the biological and mechanical systems.

Many have explored the physiology, ${ }^{1-6}$ biomechanics, $^{7-15}$ and physical aspects ${ }^{16-20}$ of rowing. However, few efforts have been made to understand the interrelationship between the biological and mechanical systems. This paper attempts to bridge these gaps by analysing rowing as an overall system driven by a biological system.

\section{SYSTEM ANALYSIS OVERVIEW}

The goal of a rowing race is to travel a set distance in the shortest possible time. Therefore, maximising average shell velocity is critical to race performance. ${ }^{13}{ }^{18}$ Average velocity results from the combined effects of propulsive effort generated by the biological system overcoming the drag forces acting on the mechanical system. ${ }^{913}$ Understanding the forces acting on the shell-oar-rower system and how these forces affect shell velocity is fundamental for identifying ways to maximise rowing performance. These forces are analysed in the following sections beginning with an analysis of the lumped shell-oar-rower system followed by analyses of the oar and of the rower.

\section{RESULTANT SYSTEM ANALYSIS}

There are basically four forces that act on the lumped shell-oar-rower system: gravitational, buoyant, drag, and propulsive (fig 1).

The equations of motion governing this system are as follows:

$\Sigma \mathrm{F}_{\mathrm{Z}}$ :

$$
\mathrm{F}_{\mathrm{BU}}-\mathrm{F}_{\mathrm{GT}}=\mathrm{m}_{\mathrm{T}} \times \mathrm{a}_{\mathrm{Tz}}
$$

where $\mathrm{F}_{\mathrm{BU}}=$ buoyant force, $\mathrm{F}_{\mathrm{GT}}=$ gravitational force acting on the shell, rower, and oar, $\mathrm{m}_{\mathrm{T}}$ $=$ mass of system, and $\mathrm{a}_{\mathrm{Tz}}=$ acceleration of system centre of mass in $\mathrm{z}$ direction;

$\Sigma \mathrm{F}_{\mathrm{X}}$ :

$$
\mathrm{F}_{\mathrm{D}}-\sum_{i=1}^{n} \mathrm{~F}_{\mathrm{Bi}}=\mathrm{m}_{\mathrm{T}} \times \mathrm{a}_{\mathrm{Tx}}
$$

where $\mathrm{F}_{\mathrm{D}}=$ drag force, $\mathrm{F}_{\mathrm{B}}=$ force acting on the blade $(i=$ counter for each blade, $\mathrm{n}$ $=$ number of blades), $\mathrm{m}_{\mathrm{T}}=$ mass of system, and $\mathrm{a}_{\mathrm{Tx}}=$ acceleration of system centre of mass in the $x$ direction. In the vertical direction, the buoyant force and the gravitational force, acting on the combined mass of the shell, rower, and oar, establish the equilibrium position. The buoyant force, $\mathrm{F}_{\mathrm{BU}}$, is proportional to the displaced volume of water, the density of water, and gravity (equation 3 ).

$$
F_{\mathrm{BU}}=\rho_{\mathrm{H} 20} \times g \times V_{\text {disp }}
$$

where $\mathrm{F}_{\mathrm{BU}}=$ buoyant force, $\rho_{\mathrm{H} 2 \mathrm{O}}=$ density of water, $\mathrm{g}=$ acceleration due to gravity, and $\mathrm{V}_{\text {disp }}=$ volume of water displaced.

Changes to the total mass of the system (equation 4) affect the displaced volume and wetted area required to balance the gravitational force:

$$
m_{T}=m_{B}+m_{O}+m_{R}
$$

where $\mathrm{m}_{\mathrm{T}}=$ mass of system, $\mathrm{m}_{\mathrm{B}}=$ mass of shell, $\mathrm{m}_{\mathrm{o}}=$ mass of oar, and $\mathrm{m}_{\mathrm{R}}=$ mass of rower. During the rowing motion, the apparent mass of 


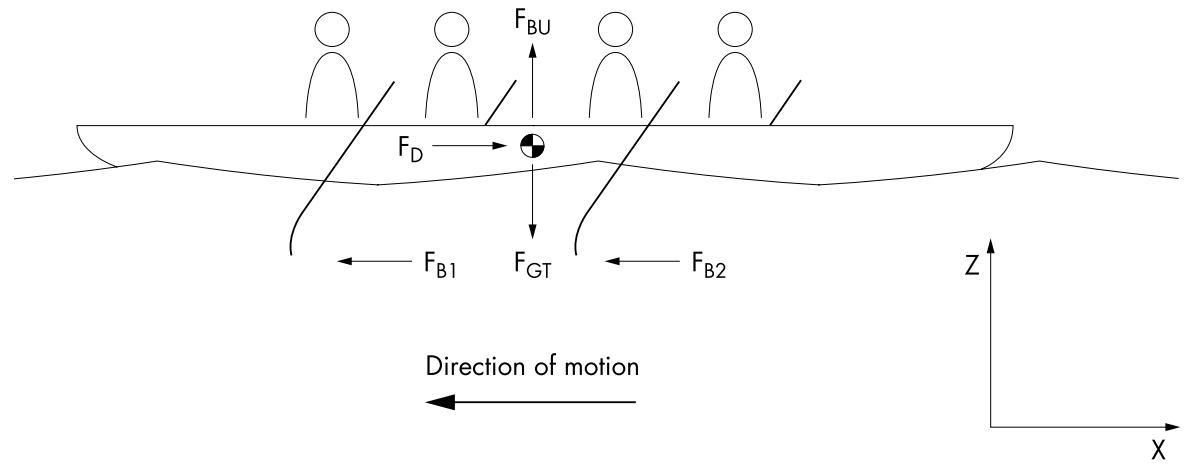

these components varies as the result of the forces acting between the shell and the rower and between the water and oar blade. The apparent changes in mass affect the resting waterline causing oscillations of $4-6 \mathrm{~cm}$ at the bow and subsequently altering the wetted and frontal cross sectional areas of the shell, affecting the drag forces acting on the system. In the horizontal direction, propulsive and drag forces act on the system. The propulsive force results from the interaction of the oar and the water, and varies depending on the number of rowers (n) and the force applied to each oar blade $\left(\mathrm{F}_{\mathrm{Bi}}\right)$. Drag forces comprised of air and hydrodynamic drag (equation 5 ) oppose the direction of movement:

$$
F_{D}=F_{A D}+F_{H D}
$$

where $\mathrm{F}_{\mathrm{D}}=$ total drag force, $\mathrm{F}_{\mathrm{AD}}=$ air drag force, and $\mathrm{F}_{\mathrm{HD}}=$ hydrodynamic drag force.

Because of the various components contributing to air drag (shell, rower, oar), and changes to their respective properties (cross sectional area, velocity, drag coefficients), rowing air drag analysis can be very complicated. The rowers' continuous motions relative to the shell during the stroke affect the instantaneous velocity, cross sectional area (table 1), and drag coefficient. However, in a rowing system, air drag only contributes $10 \%$ of the total drag for the system, ${ }^{17-19}$ and extreme fluctuations in the quantities affecting air drag result in only minor changes in the drag force. For example, an extreme vertical shell oscillation of $6 \mathrm{~cm}$ results in a $330 \mathrm{~cm}^{2}$ increase in shell cross sectional area exposed to the air. Compared with the total area, $8690 \mathrm{~cm}^{2}$, this represents only a $3.8 \%$ change (values for a Vespoli D-hull, table 1). In addition, the contribution of the oar to air drag is minimal because of the feathering of the blade and the shape of the shaft. Therefore it is often reasonable to approximate the air drag using equation (6) with constant terms for all variables except the velocity term.

where $A_{r+b}=$ cross sectional area of rower and shell $\left(A_{r}+A_{b}\right)$ and $V_{A}=$ average velocity of shell with respect to air.

Hydrodynamic drag acting on a rowing shell is composed of three drag quantities: skin, form, and wave drag:

$$
\begin{aligned}
& \mathrm{F}_{\mathrm{AD}}=\frac{1}{2} \times \rho_{\text {air }} \times \mathrm{C}_{\mathrm{D}} \times \mathrm{A}_{\mathrm{r}+\mathrm{b}} \times \mathrm{V}_{\mathrm{A}}^{2} \\
& \mathrm{~F}_{\mathrm{HD}}=\mathrm{F}_{\mathrm{HDs}}+\mathrm{F}_{\mathrm{HDf}}+\mathrm{F}_{\mathrm{HDw}}
\end{aligned}
$$
sented by equation $(8)$ :

$$
\mathrm{F}_{\mathrm{HD}}=1.25 \times \mathrm{k} \times \mathrm{V}_{\mathrm{W}}^{2}
$$
change in skin drag. tions 6 and 8):
Figure 1 Free body diagram of a shell-oar-rower system.

where $\mathrm{F}_{\mathrm{HDs}}=$ hydrodynamic skin drag, $\mathrm{F}_{\mathrm{HDf}}=$ hydrodynamic form drag, and $\mathrm{F}_{\mathrm{HDw}}=$ hydrodynamic wave drag.

It is generally accepted that skin drag contributes over $80 \%$ of the hydrodynamic drag on a racing shell ${ }^{1821}$ - that is, $\mathrm{F}_{\mathrm{HD}}=$ $1.25 \times \mathrm{F}_{\mathrm{HDs}}$-allowing total hydrodynamic drag to be repre-

where $\mathrm{k}=\mathrm{a}$ constant and $\mathrm{V}_{\mathrm{w}}=$ velocity of shell with respect to water. $\mathrm{k}$, a constant similar to the $\mathrm{C}_{\mathrm{D}}$ term in the standard fluid drag equation $\left(1 / 2 \mathrm{C}_{\mathrm{D}} \rho_{\mathrm{H} 2 \mathrm{O}} \mathrm{A}_{\mathrm{B}} \mathrm{V}_{\mathrm{B}}^{2}\right)$, depends on the wetted area and hull shape and must be determined experimentally. As the shell oscillates, the percentage increase in wetted area will have a direct effect on the constant k. For an increase of $6 \mathrm{~cm}$, using the value of $19.3 \mathrm{~cm}$ for maximum draft $^{22}$ over the length of the shell, a 9\% change in wetted area occurs during a stroke cycle (estimation made for a Vespoli D hull). For a displaced volume of $862 \mathrm{~m}^{3}$, Lazauskas ${ }^{22}$ showed that, at a Froude number of 1.5-2.1, representing the normal range for a racing shell, the coefficient of drag was around 0.0275 . At a speed of $5.5 \mathrm{~m} / \mathrm{s}$, a $9 \%$ change in $\mathrm{k}$ causes a $5 \%$

Vertical oscillation of the shell about its resting waterline only introduces minimal fluctuations to both the air and hydrodynamic drag forces. Furthermore the changes in area cause opposite changes in their respective forces; if one increases, then the other decreases. Millward ${ }^{18}$ similarly concluded that vertical forces are fairly constant and have minimal effect on rowing performance, allowing horizontal

\begin{tabular}{|c|c|c|c|c|}
\hline Area component & $\begin{array}{l}\text { Height } \\
(\mathrm{cm})\end{array}$ & Width $(\mathrm{cm})$ & $\begin{array}{l}\text { Cross sectional area } \\
\left(\mathrm{cm}^{2}\right)\end{array}$ & Notes \\
\hline $\begin{array}{l}\text { Oar blade - square } \\
\text { Oar blade - feathered } \\
\text { Oar shaft - mid-drive } \\
\text { Rigger } \\
\text { Hull - above waterline (at rest) } \\
\text { Rower - upright } \\
\text { Rower - finish/catch } \\
\text { Total frontal area above water during } \\
\text { recovery }\end{array}$ & $\begin{array}{l}25 \\
\sim 1 \\
5 \\
3 \\
10 \\
85 \\
54.6\end{array}$ & $\begin{array}{l}55(\times 2) \\
55(\times 2) \\
260(\times 2) \\
55(\times 2) \\
55 \\
60 \\
60\end{array}$ & $\begin{array}{l}2750 \\
110 \\
2600 \\
330 \\
550 \\
5100 \\
3276 \\
110+2600+330+ \\
550+5100=8690\end{array}$ & $\begin{array}{l}\text { C2 big blade, on the square, one on each side } \\
\text { C2 big blade, feathered, one on each side } \\
\text { To account for exposed portion of shaft on both sides } \\
\text { Rigger on each side } \\
50^{\circ} \text { from upright } \\
\text { Rower upright, blades feathered }\end{array}$ \\
\hline
\end{tabular}
components to be emphasised in the following sections.

The total drag equation can be simplified (combining equa-

Table 1 Sample dimensions: data for a Vespoli D-hull 8 and a Concept2 sweep oar with a big blade 


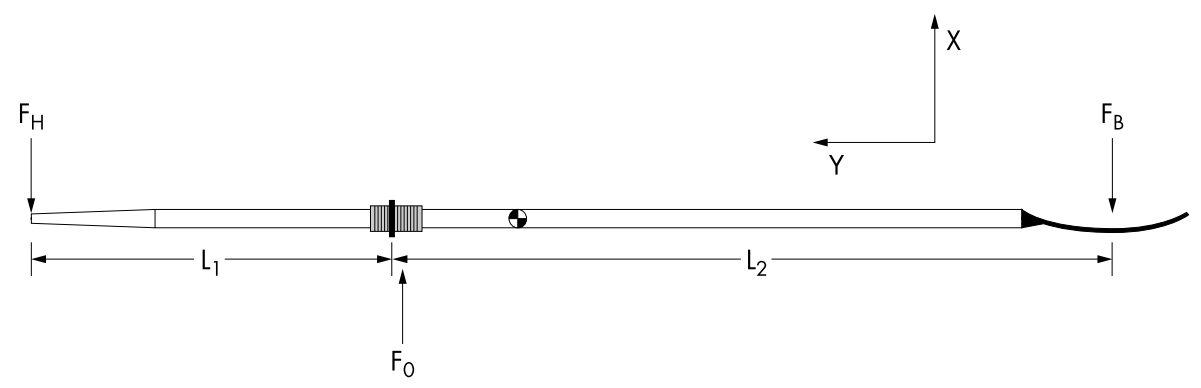

Figure 2 Free body diagram of oar forces (horizontal plane).

$$
\begin{aligned}
& F_{D}=\left(\frac{1}{2} \times C_{D} \times \rho_{\text {air }} \times A_{r+b} \times V_{A}^{2}\right)+ \\
& \left(1.25 \times k \times V_{W}^{2}\right)
\end{aligned}
$$

Therefore the propulsive force acting on a racing shell system can be expressed by combining equations (2) and (9):

$$
\begin{aligned}
& \sum_{i=1}^{n} F_{B i}=\left(\frac{1}{2} \times C_{D} \times \rho_{\text {air }} \times A_{r+b} \times V_{A}^{2}\right)+ \\
& \left(1.25 \times k \times V_{W}^{2}\right)-\left(m_{T} \times a_{T}\right)
\end{aligned}
$$

Equation (10) indicates that there are few rower-shell-oar quantities that can be changed to reduce the propulsive force required to accelerate the shell or to maintain the shell at a given velocity. $A_{\mathrm{r}}$ could be adjusted, but only at the expense of altering the rowing style to produce a smaller cross section. Reducing rower mass, the main component of system mass, would be detrimental to overall performance because, assuming equivalent fitness levels and similar equipment, heavier rowers achieve higher average velocities than lighter rowers. ${ }^{1923}$ The materials used for rowing equipment already push the limit of the strength/weight relationship and approach optimal shape for drag considerations..$^{20}$ Material coatings on the shell, such as polishes or hydrophobic polymers, may lead to a decreased skin friction drag coefficient, $\mathrm{k}$, leading to gains in rowing performance. It appears that blade force $\left(\mathrm{F}_{\mathrm{B}}\right)$ is the variable that needs to be maximised to cause an increase in the shell acceleration and to attain higher shell velocity.

\section{FORCES ACTING ON THE OAR}

The oar plays an important role in the rowing system by transmitting the force developed by the rower to the blade. Joint moments generated by the rower result in movement of the rower with respect to the shell. This causes a corresponding movement of the oar handle that is resisted by the interaction of the blade and the water. The motion of the oar is partially constrained by the oarlock, restraining the oar from sliding axially. For this analysis, a single oar is modelled, yet is representative of either a scull or sweep oar. Figures 2 and 3 are free body diagrams, and derivations for the equations of motion are provided below. (Note that the forces in figures 2 and 3 are not constrained to the vector directions shown).
The following equations of motion dictate the movement of the oar:

$\Sigma \mathrm{F}_{\mathrm{x}}$ :

$$
F_{O x}-F_{B x}-F_{H x}=m_{O} \times a_{O x}
$$

where $\mathrm{F}_{\mathrm{Hx}}=$ force on the handle in the $\mathrm{x}$ direction, $\mathrm{F}_{\mathrm{Ox}}=$ reaction force at the oarlock in the $\mathrm{x}$ direction, $\mathrm{F}_{\mathrm{Bx}}=$ force on the blade in the $\mathrm{x}$ direction, $\mathrm{m}_{\mathrm{o}}=$ mass of the oar, and $\mathrm{a}_{\mathrm{ox}}=$ acceleration along the $\mathrm{x}$ axis.

$\Sigma \mathrm{F}_{\mathrm{z}}$ :

$$
\mathrm{F}_{\mathrm{Oz}}-\mathrm{F}_{\mathrm{GO}}-\mathrm{F}_{\mathrm{Hz}}=\mathrm{m}_{\mathrm{O}} \times \mathrm{a}_{\mathrm{Oz}}
$$

where $\mathrm{F}_{\mathrm{Oz}}=$ reaction force at the oarlock in the $\mathrm{z}$ direction, $\mathrm{F}_{\mathrm{GO}}$ = gravitational force acting on the oar, $\mathrm{F}_{\mathrm{Hz}}=$ force on the handle in the $\mathrm{z}$ direction, and $\mathrm{a}_{\mathrm{Oz}}=$ acceleration along the $\mathrm{z}$ axis. $\Sigma \mathrm{M}_{\text {Blade }}$ :

$$
F_{H}\left(L_{1}+L_{2}\right)-F_{0} L_{2}=I \times \alpha \text { (within horizontal plane) }
$$

where $\mathrm{L}_{1}=$ distance between the end of the handle and the collar, $\mathrm{L}_{2}=$ distance between the collar and the blade centre of pressure, $\mathrm{I}=$ moment of inertia of oar about blade centre of pressure, and $\alpha=$ angular acceleration of oar.

The oar can be viewed as both a type I and type II lever, depending on one's frame of reference (the moving shell or the shore). The blade resists movement in the water, opposing the force applied on the handle and resulting in a reaction at the oarlock $\left(\mathrm{F}_{\mathrm{Oi}}\right)$ that is directly related to shell acceleration. ${ }^{24}$ This emphasises the importance of the lever arm lengths in the rowing system (equation 13). The load applied by the oar on the oarlock is transmitted to the hull through the rigger. A detailed analysis of the rigger forces will not be provided, as the resultant force at the oarlock suffices to represent the effect on the hull. The component oarlock force contributing to propulsive effort is $\mathrm{F}_{\mathrm{o}} \cos \theta$, where $\theta$ is the oar angle with the shell.

If the overall reaction forces at the oarlocks are unbalanced, or are applied at alternate times, they will cause a net torque about the centre of the shell. This upsets the balance of the shell and possibly alters the direction of motion, creating greater drag and leading to a slower time. ${ }^{13}$ To achieve faster average velocity, rowers must apply forces on the oar in synchrony. ${ }^{14}$

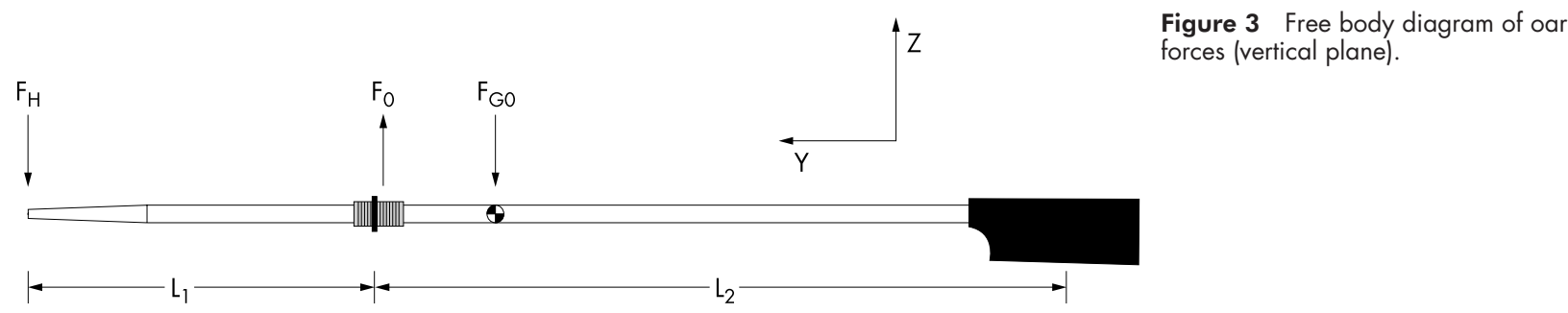




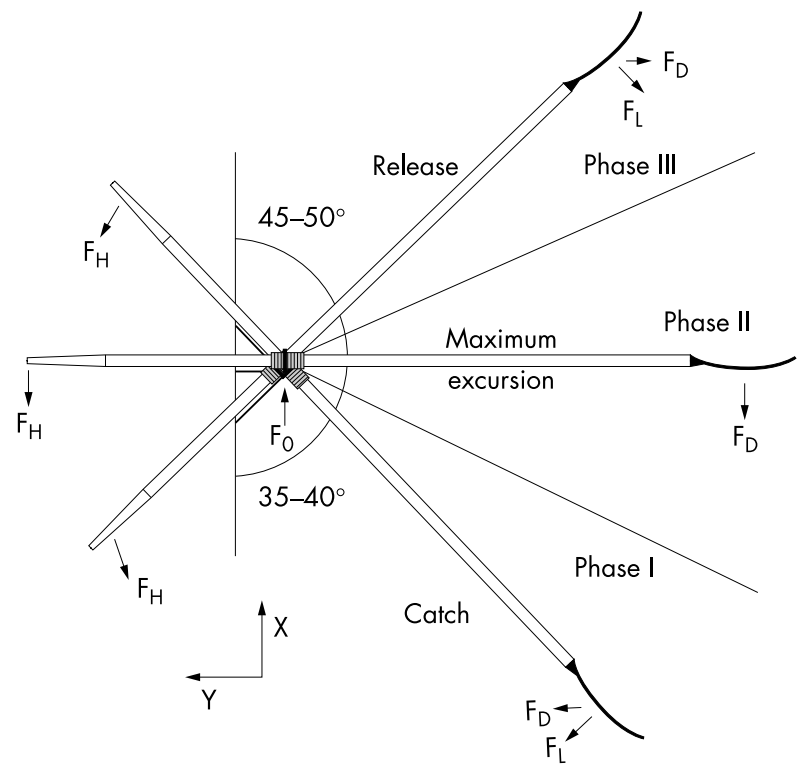

Figure 4 Oar positions.

The oar prescribes an arc in the water as the rower moves through the stroke. Force is generated during the entire range of motion of the oar. ${ }^{15}$ By design, the blade generates force through its interaction with the water by two mechanisms: lift and drag..$^{25}$

$$
\mathrm{F}_{\mathrm{By}}=\mathrm{F}_{\mathrm{Dy}}+\mathrm{F}_{\mathrm{Ly}}
$$

where $\mathrm{F}_{\mathrm{DY}}=$ drag component of blade force in the y direction and $\mathrm{F}_{\mathrm{Ly}}=$ lift component of blade force in the y direction.

$$
F_{B x}=F_{D x}+F_{L x}
$$

where $\mathrm{F}_{\mathrm{Dx}}=$ drag component of blade force in the $\mathrm{x}$ direction and $\mathrm{F}_{\mathrm{Lx}}=$ lift component of blade force in the $\mathrm{x}$ direction.

The proportion of lift and drag forces contributing to propulsive force vary depending on the angular displacement of the oar relative to the shell, as this controls the position and path of the blade in the water (fig 4). ${ }^{26}$ During the first and third phases, lift is the main source of force on the blade, as the blade moves sideways relative to the shell. In contrast, the second phase relies mainly on drag to generate the blade force. Factors affecting propulsive force output approach optimum values during this phase as shown by the cosine term approaching maximum, the rower nearing a position of maximum activation, ${ }^{12}$ the blade approaching its furthest distance from the boat, and the blade force being generated by drag. The magnitude of force acting on the blade varies during the stroke depending on the oar position, the blade's shape, and the fluid flow surrounding the blade. (Note that the forces in fig 4 are not constrained to the vector directions shown.)

Lift and drag are both highly dependent on the relative velocity between the water and the blade. The lateral displacement of the blade as it prescribes the arc in the water provides the movement required to produce lift, while slippage of the blade in the water provides the dynamics required for drag. ${ }^{27}$ The displacement of water, estimated at $0.1 \mathrm{~m}$ by Young and Muirhead $^{28}$ for a single scull, is required for conservation of momentum. However, blade slippage should not be excessive because the aim of the stroke is to displace the shell and not the water.

Oar kinematics are directly influenced by the rigging, which affects the lever ratios. Changes to the inboard lever arm alter
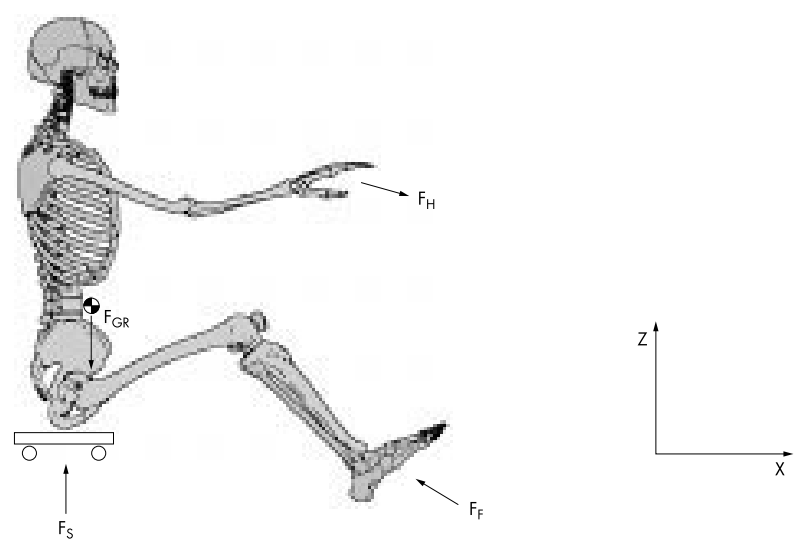

Figure 5 Free body diagram of rower forces.

the relation between the rower's contraction velocities and oar angular displacement. For example, decreasing the inboard lever arm without altering the rower's movement increases the blade velocity and changes the drag and lift forces acting on the blade. If the net propulsive force is decreased, then the rower will have to increase the stroke rating to deliver equivalent power. A higher blade velocity transfers more momentum to the water, resulting in greater water displacement. A rower would need to pull faster to maintain the same blade velocity for an increased inboard lever arm. High handle speeds could result in early muscle fatigue or other detrimental effects. Recommended rigging tables are readily available from equipment manufacturers. Current rigging philosophy tends to blindly follow recommended guidelines while overlooking possible performance gains afforded by individually adjusting the inboard length to match physical and physiological attributes of a specific rower. Variations in muscle type or anthropometrics could warrant an adjustment of the rigging, allowing the athlete's muscles more favourable force-velocity behaviour. Therefore, the mechanical system, represented by the oar and the rigging, should be properly matched to the physiological system, the rower, to result in maximum sustainable power delivery. ${ }^{7}$ Further research is required to quantify the potential gains available by matching the rigging to the specific rower. An analysis of the rower is warranted to further understand the factors that contribute to a rower's ability to apply force and displace the oar handle.

\section{FORCES ACTING ON THE ROWER}

Three forces act on the rower: forces at the foot, the seat, and the hand (fig 5). The rower generates the foot stretcher force directly and acts as the mechanical link between the foot stretcher force and the oar handle force.

Equations of motion for the rower are given by: $\Sigma \mathrm{F}_{\mathrm{x}}$ :

$F_{H x}-F_{F x}=m_{R} \times a_{R x}$

where $\mathrm{F}_{\mathrm{Hx}}=$ force exerted on the hands in the $\mathrm{x}$ direction, $\mathrm{F}_{\mathrm{Fx}}$ $=$ force exerted on the feet in the $\mathrm{x}$ direction, $\mathrm{m}_{\mathrm{R}}=$ mass of the rower, and $\mathrm{a}_{\mathrm{Rx}}=$ acceleration of the rower in the $\mathrm{x}$ direction.

$\Sigma \mathrm{F}_{\mathrm{z}}$

$\mathrm{F}_{\mathrm{Fz}}+\mathrm{F}_{\mathrm{Sz}}-\mathrm{F}_{\mathrm{Hz}}-\mathrm{F}_{\mathrm{GR}}=\mathrm{m}_{\mathrm{R}} \times \mathrm{a}_{\mathrm{Rz}}$

where $\mathrm{F}_{\mathrm{Hz}}=$ force exerted on the hands in the $\mathrm{z}$ direction, $\mathrm{F}_{\mathrm{Sz}}=$ force exerted by the seat in the $\mathrm{z}$ direction, $\mathrm{F}_{\mathrm{Fz}}=$ force exerted 

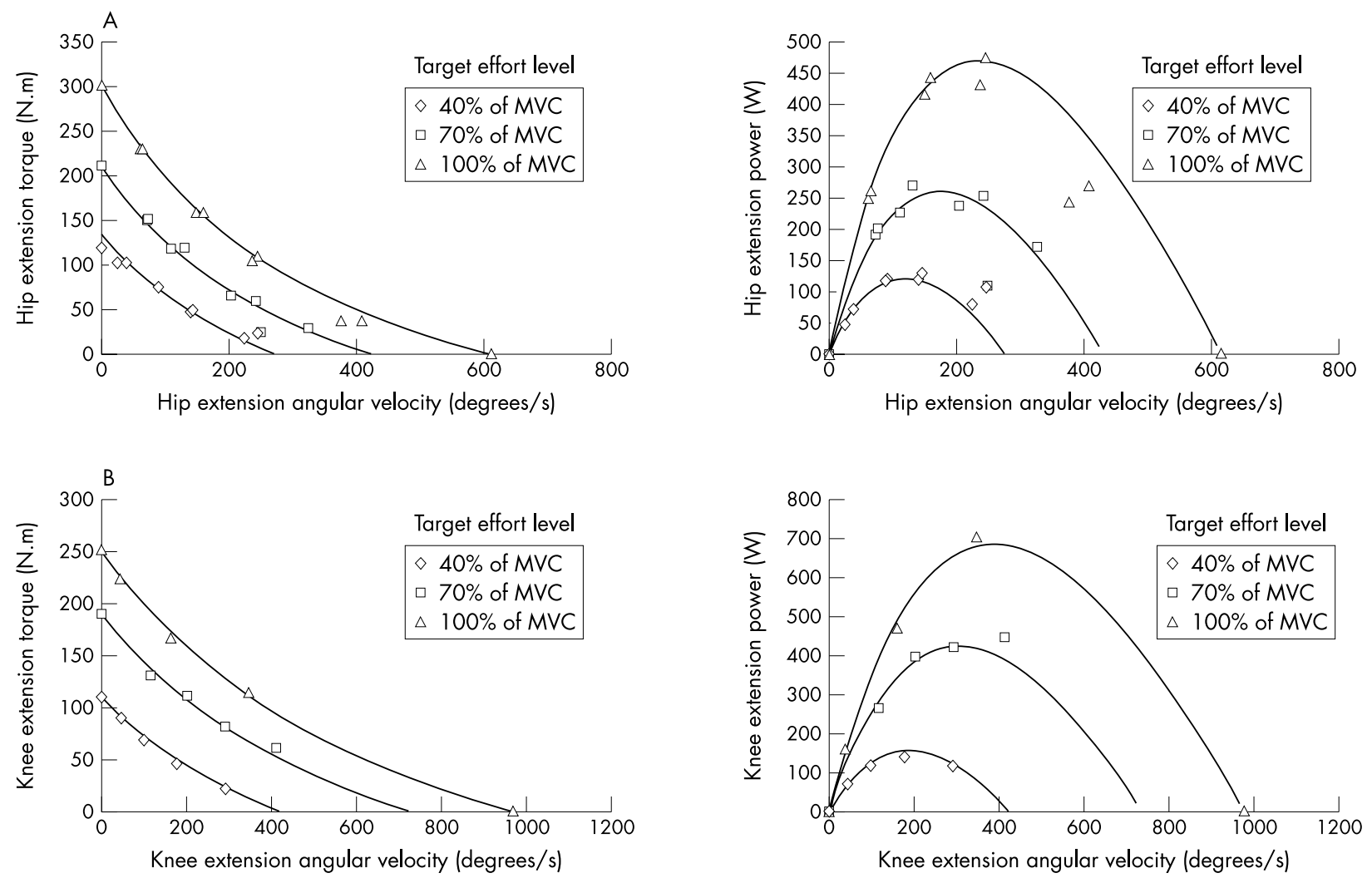

Figure 6 Torque-angular velocity profiles and power-angular velocity profiles for $(A)$ the hip and (B) the knee of one subject producing three different effort levels. Curves represent empirical model of experimental data. Data represent a subset of data collected and published by Hawkins and Smeulders. ${ }^{31} 32$

on the feet in the $\mathrm{z}$ direction, $\mathrm{F}_{\mathrm{GR}}=$ force of gravity on rower, $\mathrm{m}_{\mathrm{R}}=$ mass of the rower, and $\mathrm{a}_{\mathrm{Rz}}=$ acceleration of the rower in the $\mathrm{z}$ direction.

$$
F_{G R}=m_{R} \times g
$$

The force developed at the hand is critical to the propulsive force developed at the blade as shown in the previous section. The equations of motion derived above show that the force developed at the hand depends on the force on the foot stretcher and the acceleration of the body (equation 15). Other forces play little role in the propulsion of the shell.

The rowing seat supports only a vertical force because of its rolling motion in the rowing shell. Friction between the rower and the seat causes the seat to move along with the rower during the rowing motion. Force acting in the vertical direction may alter the apparent mass or mass distribution of the system, but as shown previously this has little effect on boat propulsion or drag forces. Therefore, rowing performance depends largely on the rower's ability to develop large foot stretcher forces and to transmit those forces to the hand.

The force that a rower can apply to the oar handle depends on the musculoskeletal forces or joint torques that can be generated and transmitted. ${ }^{12}{ }^{29}$ If a rower can produce a large pushing force on the foot stretcher, but the back cannot support this force, then force transmission to the oar will be reduced because of back flexion. The rower must have matching musculoskeletal strength across joints or a sequential phasing of joint movements to maximise the impulse applied to the oar. Leg, back, and arm segments do not have equivalent force generating capacity. Thus, the sequential loading of leg, back, and arms results in each segment being loaded appropriately as the segment velocities increase and peak segmental forces decrease. Further, the kinematics of the rower's movement should maximise the power producing capability of the muscles. This requires impedance matching, or matching the rowers' and oars' kinetics and kinematics so as to maximise the power produced.

Muscle force and joint moments depend on the velocity of movement (fig 6). As the joint angular velocity increases, the muscle torque produced about the joint decreases for all effort levels. There is an optimal angular velocity for power production that depends on the effort level. The hip and knee angular velocities that allow maximum power to be developed by the individual depicted in fig 6 producing a $40 \%$ effort would be approximately 150 and $200 \%$ s respectively. This suggests that there should be an ideal stroke rating and rigging setup to produce appropriate contraction velocities and muscular effort levels to displace the shell effectively. ${ }^{70}$ Optimal stroke rating is further constrained by the unloaded cost of moving the limbs, blood flow within the limbs, and ventilation. Higher stroke rates increase the proportion of time that the muscles are contracted, whereas lower stroke rates increase the intramuscular forces. Both of these concepts impact the ability of blood to flow within capillaries and replenish the cells. Therefore an optimum stroke rate exists allowing proper oxygen delivery and waste removal. Higher stroke rates cause an increase in ventilation frequency, increasing the energetic cost of breathing. Therefore at higher stroke rates, less oxygen is available for the muscles, reducing the available external work at maximal aerobic power.

The rowing system is non-optimised, as the intermittent propulsion leads to lower average velocities than a constant velocity system. ${ }^{14}{ }^{18} 20$ Higher stroke rating leads to smaller oscillations in the system velocity. ${ }^{20}$ This places large physiological demands on the rower, requiring greater force generation, because of the dependency of hydrodynamic drag on system velocity, and a higher fitness level to sustain the increased force production. 
The rower undergoes large changes in acceleration during the stroke. During the drive, the rower is accelerating faster than the overall system, and during the recovery the rower moves in a direction opposite to the net displacement. This presents unique dynamics for the rower, causing a large amount of extraneous movement independent of the shell for about $70-80 \%$ ( 1600 of $2000 \mathrm{lbs}$, for an eight) of the system's mass. Therefore the rower's momentum plays an important role in system dynamics, ${ }^{21}$ reducing the velocity oscillations inherent due to the intermittent thrust. ${ }^{7}$ Conservation of momentum of the system after the stroke is completed forces the shell forward as the crew rolls back up to the catch position. For a $1 \mathrm{~m}$ displacement of the rower, about $80 \mathrm{~cm}$ of that is the shell sliding under the rower. Maximum forward shell velocity occurs during the recovery, and the minimum shell velocity is experienced during arguably the most powerful segment of the stroke, the drive. ${ }^{33}$

By examining a rower's joint torque-velocity and torqueangle profiles, the setup of the rigger can be adjusted such that power delivery by the rower is augmented by the lever action of the oar to provide maximum sustainable power during the stroke. In addition, the concept of a force or power profile $^{8-1014243435}$ can be used to adjust the "weighting" (adjusting lever arm lengths) of the oar depending on a rower's optimised contraction speeds and force delivery. These concepts are amplified when examining multiple rower shells, ${ }^{15}$ as the benefits of having rowers with similar force and power profiles can be explored.

\section{CONCLUSION}

In competitive rowing, the goal of the athlete is to complete a set distance in the shortest time possible. This dictates that the rower should work to improve power delivery during the rowing motion and that the overall system should be designed to maximise average velocity. This discussion highlights several key points that affect system velocity and therefore rowing performance.

- Average system velocity is primarily affected by the forces acting in the direction of motion: propulsive force acting on the blade and drag forces acting on the rower and shell.

- Drag forces acting on the rower and shell depend on the frontal area of the rower and shell, the density of water and air, the coefficients of drag for the shell and rower, and approximately the square of the velocities of the shell relative to the water and the rower relative to the air.

- It appears that, of the drag parameters listed above, it is likely that significant changes in rowing performance can be gained by reducing velocity fluctuations of the shell relative to the water or the rower relative to the air, and that small performance gains may result from new surface coatings designed to reduce shell skin drag. Modifications to other drag parameters will probably result in slight drag reductions unless accompanied by major design changes in the shell or the rower's body position.

- Drag forces depend approximately on the square of the relative velocities of the rower with respect to the air and the shell with respect to the water. Velocity fluctuations in either the shell or the rower require greater propulsive force to maintain a given average system velocity than if the velocity was kept constant.

- Fluid drag acting on the shell constitutes about $90 \%$ of the total drag acting on the system, and therefore minimising oscillations in shell velocity provides the greatest opportunity for reducing drag forces.

- Propulsive force to the system occurs at the oar blade.

- Oar blade force depends on drag and lift forces acting between the blade and the water, which are affected by the

\section{Take home message}

Rowing performance can be improved by two basic mechanisms: increasing the propulsive impulse and decreasing the drag impulse applied to the system during a stroke cycle. Current rowing practices should be critically evaluated with these ideas in mind and based on fundamental physical and physiological principles. Characterising the interactions between the mechanical system (the rowing shell and oar) and the biological system (the rower) will lead to refinements in rower selection and pairing, rigging setup, and rowing strategy that will increase rowing performance.

force and movement developed by the rower at the handle as well as the rigging setup that affects the lever system.

- The rower generates the foot stretcher force directly and acts as the mechanical linkage between the foot stretcher force and the oar handle force.

- Oar handle force and movement are affected by the joint strength and torque-velocity characteristics of the rower.

- Maximising sustainable power requires a matching of the rigging setup and blade design to the rower's joint torque-velocity characteristics.

- Coordination and synchrony between rowers in a multiple rower shell affects overall system velocity.

Rowing performance can be improved by two basic mechanisms, either increasing the propulsive impulse or decreasing the drag impulse applied to the system during a stroke cycle. Results from these analyses suggest that there are several areas of research that may lead to improvements in these two mechanisms. Firstly, drag forces/impulses can be reduced by minimising the shell velocity fluctuations. This may be achieved through a rowing strategy in which pairs of rowers row out of phase, providing a more continuous impulse to the system. This strategy was apparently tried and shown to be successful before being banned in the $1930 \mathrm{~s},{ }^{36}$ validating the importance of minimising shell velocity fluctuations. Secondly, recovery kinematics should be studied to better understand the impact of the rower's movement on the velocity fluctuation of the shell, and its impact on drag. Thirdly, the oar blade design and rigging setup need to match rower strength and torque-velocity profiles. Fourthly, force-time profiles should be better understood to identify specific components of a rower's biomechanics that can be modified to achieve greater force generation. Fifthly, crew selection principles may benefit from the use of force-time profiles. Individual athletes may be selected on the basis of their ability to generate large propulsive impulses, and pairing of athletes may be determined by matching force-time profiles to generate a balanced cumulative blade force. Success in any of these areas requires integration of information from basic studies of physiology and mechanics.

\section{Authors' affiliations}

A Baudouin, D Hawkins, Human Performance Laboratory, University of California, Davis, California, USA

\section{REFERENCES}

1 Hagerman FC. Applied physiology of rowing. Sports Med 1984;1:303-26.

2 Jensen K. Test procedures for rowing. FISA Coach 1994;5:1-6.

3 Mahler DA, Nelson WN, Hagerman FC. Mechanical and physiological evaluation of exercise performance in elite national rowers. JAMA 1984;252:496-9.

4 Mazzone T. Kinesiology of the rowing stroke. NSCA Journal 1988;10:4-11. 
5 Roth W, Schwanitz $\mathrm{P}$, Bas $\mathrm{P}$, et al. Force-time characteristics of the rowing stroke and corresponding physiological muscle adaptations. Int J Sports Med 1993;14(suppl 1):S32-4.

6 Steinacker JM. Physiological aspects of training in rowing. Int J Sports Med 1993;14(suppl 1):S3-10.

7 Celentano F, Cortili G, Di Prampero PE, et al. Mechanical aspects of rowing. J Appl Physiol 1974;36:642-7.

8 Henry JC, Clar RR, McCabe RP, et al. An evaluation of instrumented tank rowing for objective assessment of rowing performance. J Sports Sci 1995:13:199-206.

9 Ishiko T, Katamoto S, Maeshima T. Analysis of rowing movements with radiotelemetry. In: Matsui H, Kobayashi K, eds. Biomechanics II. Champaign, IL: Human Kinetics, 1983:816-21.

10 Macfarlane DJ, Edmond IM, Walmsley A. Instrumentation of an ergometer to monitor the reliability of rowing performance. J Sports Sci 1997: 15:167-73.

11 Nelson WN, Widule DJ. Kinematic analysis and efficiency estimate of intercollegiate female rowers. Med Sci Sports Exerc 1983;15:535-41.

12 Rodriguez RJ, Rodriguez RP, Cook SD, et al. Electromyographic analysis of rowing stroke biomechanics. J Sports Med Phys Fitness 1990;30:102-9.

13 Schneider E, Hauser M. Biomechanical analysis of performance in rowing. In: Morecki, A, Kazimierz, F, Krizystof K, et al, eds. Biomechanics VII-B. Baltimore: University Park Press, 1981:430-5.

14 Smith RM, Spinks WL. Discriminant analysis of biomechanical differences between novice, good and elite rowers. J Sports Sci 1995; 13:377-85.

15 Wing A, Woodburn C. The coordination and consistency of rowers in a racing eight. J Sports Sci 1995;13:187-97.

16 Brearley MN, de Mestre NJ. Modeling the rowing stroke and increasing its efficiency; 3rd Conference on Mathematics and Computers in Sport, Bond University, Queensland, Australia, 30 Sept-2 Oct 1996. Mobart, 1996:35-46.

17 Lazauskas L. A performance prediction model for rowing races. http://www.maths.adelaide.edu.au/Applied/llazausk/hydro/rowing/ stroke/stroke.htm. 24 Dec 1997.

18 Millward A. A study of the forces exerted by an oarsman and the effect on boat speed. Journal of Sports Sciences 1987;5:93-103

19 Sanderson B, Martindale W. Towards optimizing rowing technique. Med Sci Sports Med 1986;18:454-68.

20 Senator $M$. Why sliding seats and short stroke intervals are used for racing shells. J Biomed Eng 1981;103:151-9.

21 Dudhia A. Basic Physics of Rowing. http://www-atm.atm.ox.ac.uk/ rowing/basics.html. 14 August 2000.

22 Lazauskas L. Rowing shell drag comparisons. http:// www.maths.adelaide.edu.au/Applied/llazausk/hydro/rowing/real/ realrow.htm. 17 Jan 1998

23 Dudhia A. Effect of weight in rowing. http://www-atm.atm.ox.ac.uk/ rowing/weight.html. 28 October 282000.

24 Ishiko T. Biomechanics of rowing. In: Wartenweiler J, Jokl E Vredenbregt J, eds. Biomechanics II. Basel: S Karger, 1971:249-52.

25 Young K. Hydrodynamic lift in the sculling (rowing) stroke. http://courses.washington.edu/phys208/scull.lift.html. 5 June 1997.

26 Dreissigacker P, Dreissigacker D. Oars: theory and testing: theory. XXIX FISA Coaches Conference, Sevilla, Spain, 2000. http://

rowing.concept2.com/concept2/v02/products/oars/oartheory.asp.

27 Dudhia A. FAQ: Physics of rowing. http://www-atm.atm.ox.ac.uk/ rowing/physics.html\#weight. 7 April 2001.

28 Young K, Muirhead R. On-board-shell measurements of acceleration. http://courses.washington.edu/phys208/shell.acceleration.html. 1 Dec 1991.

29 Bompa TO. Technique and muscle force. Canadian Journal of Applied Sport Science 1980;5:245-9.
30 Hartmann U, Mader A, Wasser K, et al. Peak force, velocity, and power during five and ten maximal rowing ergometer strokes by world class female and male rowers. Int J Sports Med 1993;14:S42-5.

31 Hawkins D, Smeulders M. Modeling the relationship between knee joint torque, velocity, and muscle activation: Considerations for musculoskeletal modeling. J App/ Biomech 1998;14:141-57.

32 Hawkins D, Smeulders M. Modeling the relationship between hip extension torque, velocity, and muscle activation. J Appl Biomech 1999;15:253-69

33 Martin TP, Bernfield JS. Effect of stroke rate on velocity of a rowing shell. Med Sci Sports Exerc 1980;12:250-6.

34 Asami T, Adachi N, Yamamoto K. Biomechanical analysis of rowing performances. In: Morecki A, Kazimierz F, Krizystof K, et al, eds. Biomechanics VII-B. Baltimore: University Park Press, 1981:442-6.

35 Hawkins D. A new instrumentation technique for training rowers. J Biomech 2000:33:241-5.

36 MacMillan R. Correspondence note to editor. The Mathematical Gazette 2000;84:316.

\section{COMMENTARY}

Rowing is a sport that appeals to the biomechanist because of its technical complexity. Rowing also appeals to exercise physiologists because of the extreme physical qualities that are required for success at the highest levels. The authors present a clear and concise treatment of the biomechanical factors that affect rowing performance. Perhaps more importantly, they also begin to take up the important discussion of how mechanical and physiological constraints interact. Optimal rowing technique cannot be determined by physics alone, because the force producer is a biological system that responds non-linearly to changes in muscle contraction frequency, relative intensity, etc. Rowing is a highly advanced discipline where both the athletes and the equipment are already being pushed to their "engineering limits". Further developments in rowing velocity may well depend on better integrative research using biomechanical and physiological data simultaneously to optimise technique at the individual and team level. This review moves us in the right direction.

The authors also identify minimisation of boat velocity fluctuations as an important focus for achieving better performances in the future. Is asynchronous rowing the answer for the future? I doubt it. But then again, the sliding seat had its detractors too!

S Seiler

Institute for Sport, Agder University College, Kristiansand, Norway; Stephen.Seiler@hia.no 